\title{
The Impacts of Urbanization Processes on Human Rights
}

\author{
Sonja Deppisch모 Mert Can Yilmaz ${ }^{2}$ \\ ${ }^{1}$ Global Change \& Land-Use Strategies, Hafen City University Hamburg, Hamburg, Germany \\ ${ }^{2}$ HafenCity University Hamburg, Hamburg, Germany \\ Email: sonja.deppisch@hcu-hamburg.de,mert.yilmaz@hcu-hamburg.de
}

How to cite this paper: Deppisch, S., \& Yilmaz, M. C. (2021). The Impacts of Urbanization Processes on Human Rights. Current Urban Studies, 9, 355-375. https://doi.org/10.4236/cus.2021.93022

Received: June 14, 2021

Accepted: July 23, 2021

Published: July 26, 2021

Copyright $\odot 2021$ by author(s) and Scientific Research Publishing Inc. This work is licensed under the Creative Commons Attribution-NonCommercial International License (CC BY-NC 4.0). http://creativecommons.org/licenses/by-nc/4.0/ (c) (i) (5) Open Access

\begin{abstract}
Urbanization is ongoing and its processes infringe upon human rights, along with creating opportunities for people. This systematic literature review gives an overview of the state of research on the impacts of urbanization processes on human rights. The primary literature corpus exists of case studies in the regions of developing and to a lesser extent of emerging and, still lesser extent, developed countries. Urbanization has mainly impacted socio-culturaleconomic rights, such as an adequate standard of living or access to medical services; however, other human rights are also of concern, such as non-discrimination. Apart from those, the state of research also considers the linkages to other global change processes, contextual settings, and local problems such as environmental degradation. It also reports on the solutions to overcome the adverse impacts through planning, fair access rights, and sustainable land use.
\end{abstract}

\section{Keywords}

Urbanization Processes, Human Rights, Vulnerable Groups, Systematic Literature Review

\section{Urbanization in Context}

The city is a unique product of socio-economic activities and technological developments, which tend to affect every aspect of reality as it comes into existence, such as inhabitants' physical environment and socio-cultural settings (Davis, 1955). As a part of human life for thousands of years, it is now a dominant element of the vast majority of global population due to constant massive expansion and global change processes such as industrialization, internal and external migration, land-use changes, and climate change (Petrasek, 2014; Ray \& Borer, 
2018). Next to cities and megacities being the hotspots of social and cultural developments in our time, (rapid) urbanization processes are bearing substantially severe consequences. However, the experience is uneven for the people in different contexts and with varying backgrounds due to the various inequalities and uneven distribution of power concerning the different sources of power; furthermore, these issues undoubtedly host social problems and human rights concerns in the urban landscape and for the people living in such areas (Ray \& Borer, 2018).

The process of urbanization and associated problems are proceeding; therefore, urban research and cognate disciplines have been exploring, explaining, and criticizing its future direction and potentialities. However, the research is often not comprehensive, reflects single-sided pictures, and lacks the interrelation with other global change processes. Most of the reviewed literature displays a direction on relations and viewpoints of specific human rights consequences or solutions (Rossi-Espagnet, 1983; Cohen, 2006) in one locality or a region (Alkema et al., 2013; Ooi \& Phua, 2007) for a particular type of affected groups (Wisner, 1995). Moreover, there is no coherent and comprehensive article reviewing the link between urbanization processes and human rights. The added value of this research is to give an overview and to bring together very different and broadly spread existing literature, to list and (a) analyze urbanization as a cause and (b) impacts on human rights as an effect in different geographic locations.

Urbanization is rapid, and it is crucial to understand the impacts of this change thoroughly. Hence, this paper aims not to appraise each shred of empirical evidence concerning the link between urbanization processes and human rights, nor to endorse one side in the ongoing debate. Instead, it provides an overview of the published discourse of the impacts of urbanization processes on urban dwellers' human rights and their interplays with contextual factors and global change processes by analyzing and synthesizing so far published results identified within the literature review.

\subsection{Urbanization Processes Worldwide}

Several factors impact the substantial population growth in cities, e.g., natural increase (Ray \& Borer, 2018), rural-to-urban migration, and urban sprawl and rural-to-urban spatial transformation (United Nations, 2019b). However, data is a challenge to analyze urbanization due to countries' self-reporting and diverse classifications of what a city is (Uchida \& Nelson, 2010). Even if there is no unanimous definition nor consensus of what urbanization means, and correspondingly a city illustrates, it is a changeover of demographics from a dispersed rural area to a relatively dense urban settlement and eventually becoming more urban (McGranahan et al., 2016). Nonetheless, it is indisputable that an ever-increasing majority of people will continue to settle in urban areas while the urbanization process further continues (Vlahov, 2002).

The proportion of the global urban population has gone ahead very fast and 
reached proportions far more generous during the last century than at previous times in the world history (Davis, 1955; Vlahov, 2002). United Nations (2019a) highlights that the world is more urban than ever, with the urban population exceeding the rural population in 2017. The report states that the world reached 7.7 billion in mid-2019 and expects to reach 8.5 billion in 2030, where urban areas virtually embody all the expected growth by around $90 \%$ of the growth occurring in Asia and Africa. Thus, urbanization is a determining factor upon human rights issues with a more than four-fold growth of urban population, from an estimated 0.8 billion to an estimated 4.2 billion between 1950 and 2018, resulting in the proportion of urban rising from 30\% in 1950 to $55 \%$ in 2018 (United Nations, 2019b).

\subsection{Contextual Differences}

Urbanization is a global phenomenon, and human rights violations do not change based on location; nonetheless, regional differences are apparent when we look at its impacts on human rights (Mihr, 2010: p. 4). Developing countries encounter more significant urbanization challenges than developed ones (Henderson, 2002) since urbanization increases at rates much higher at comparable development levels and takes place in the absence of significant industrial expansion (Preston, 1979; Ray \& Borer, 2018).

Developing countries have fast-growing economies and an increasingly young population since their cities typically offer tangible economic benefits (Glaeser \& Steinberg, 2017). However, in many parts of these regions, there are still contextual conditions such as authoritarianism, religious dogmatism, defective democracies, as well as non-democratic governance structures (Mihr, 2010: p. 4). Thus, rapid urbanization and influencing processes impact human and urban development more substantially (Henderson, 2002).

\subsection{Urbanization Definitions}

Most analysts rely on the United Nations standardized definition of urban localities with population under 20,000 and cities with population above 100,000 residents (Kasarda \& Crenshaw, 1991), and most scholars often oversimplify urbanization to a simple criterion-a shift in population size within a bounded area (Dorélien et al., 2013; Hussain \& Imitiyaz, 2018). However, it is a multifaceted phenomenon with myriad dimensions. Although the demographic definition is generally accepted, the interpretation is far from homogenous across countries, regions, and territories in terms of socio-political and administrative differentiations (Gibbs, 1966; Ooi \& Phua, 2007). Urbanization is a process, not an outcome, where social and economic activities shift people toward and concentrate in the cities. Although there might be certain drawbacks, Lampard (1965) outlines three broad conceptions of urbanization, i.e., population concentration (demographic approach), the shift from the principal occupation of the working population (structural approach), and changing social value systems (behavioral 
approach).

The demographic approach refers to the process of population distribution and concentration by the percentage of the population living in a settlement, the growth in the dweller numbers and size and total area occupied by a settlement (Davis, 1965; Hauser \& Duncan, 1959; Hussain \& Imitiyaz, 2018; Lampard, 1965; Mitchell, 1956; Tisdale, 1942; United Nations, 2019b; Vlahov, 2002). Lampard (1965) accepts, and the United Nations use, this approach superior to others; however, there are disputes over the cut-off point of what a city is and what urbanization of former rural communities is (Hussain \& Imitiyaz, 2018; Yilong, 1996).

The structural approach refers to the transition in economic activity from a small community concerned chiefly or solely with agriculture to dense and nonagricultural communities principally centered in industry, government, trade, manufacture or associated services (Banerjee \& De, 2014; Davis, 1965; Hussain \& Imitiyaz, 2018; Lampard, 1965). However, the ambiguity lies in the difficulty of determining the principal occupation of the working population in small communities (Hussain \& Imitiyaz, 2018).

Individuals or communities experience the behavioral approach over time, as the socio-economic character of the place is going through the process of urbanization changes in terms of the feelings, behaviors, and the thoughts of people in their social values (Anderson, 1959; Banerjee \& De, 2014; Hussain \& Imitiyaz, 2018; Mitchell, 1956). It is a constant process and occurs due to the transition from a small homogeneous community to a large heterogeneous society. Conclusively, urbanization can be portrayed as a transition of a settlement considering demographic, spatial, socio-economic, cultural patterns through events and conditions which make concentration both possible and desirable.

\subsection{Intertwined Global Change Processes}

Urbanization is a fundamentally complex and adaptive process that is intertwined with numerous socio-economic forces and environmental matters in various circumstances (Hawley, 1967; Lampard, 1965). The process of urbanization, as a matter of fact, emerges following technological advancements and the paradigm shift of the production sector, resulting in expansion of infrastructure, transport, and communication, and later it tends to pull people into urban areas creating migration flows and demographic trends in the urban residents (Banerjee \& De, 2014; Hussain \& Imitiyaz, 2018). Furthermore, urbanization leads to simultaneous change processes in terms of globalization, land-use changes, and environmental phenomena (Simon et al., 2004).

Urbanization and these interlocking global processes may bear positive as well as negative outcomes because of insufficient planning and urban management conditions on human health, livelihoods, and the environment such as higher housing prices, crime, traffic accidents and congestions, contagious diseases and health costs as a consequence of exposure to high levels of air and water pollu- 
tion (Henderson, 2002). These negative externalities require competent public management and democratic governments to cope and deliver improvements such as clean water or public safety (Glaeser \& Steinberg, 2017). The study briefly follows with the foundations of human rights, the research process and the methods, the literature review and discussion results, and the conclusion.

\section{Human Rights and International Treaties}

Human rights are also a vast and contested topic with reference to their grounds (Tasioulas, 2012: p. 20), which are undergoing different interpretations of what they refer to and how they can be justified and implemented in different legal systems (see, for instance, an overview in Corradetti, 2009). The contested areas in a philosophical sense are manifold, but with reference specifically to our topic laid down here, it is the discussion on the human rights holders and, accordingly, of the bearers of the duties of interest (see Tasioulas, 2012: p. 20 ff.). Furthermore, with reference to the impacts of urbanization on human rights, we touch upon mainly welfare-oriented rights, as further illustrated below. Those are also contested, especially as they pose substantial, mainly economic, burdens on the bearers of the duties to fulfill them, as in some contexts, the (if so identifiable) direct bearers are unable to fulfill their obligations (Heilinger, 2011: pp. 185-188). With respect to that discussion and relating this to the discussion of the sustainable development goals, the global human community can also be subsumed to be the moral duty bearer in those cases. This brings us back to the reason why we conducted this review.

The aim of this paper, however, is not to discuss those above-mentioned contested issues with specific reference to human rights, led in philosophy and (international) law, but instead, to analyze the current state of research on urbanization's impacts on human rights. For this purpose, we refer here to the human rights designated in the international treaties and declarations. With reference specifically to urbanization, mainly rights displayed in the binding International Covenant on Economic, Social and Cultural Rights (ICESCR) are impacted, which came into force in and is at the moment ratified by 170 Nation States (United Nations, 2020). Also, they are displayed in the Universal Declaration on Human Rights of 1948 of the United Nations, which laid out the human rights initially at an international level, but in comparison to the before-mentioned treaty, it is a declaration and not a treaty, and in addition to that it is not binding. The human rights agreed upon in the international treaties retain their validity by being implanted in the signing states' domestic laws. Moreover, as Corradetti (2009: p. 130) states that there is an essential difference of having a right: "To obtain something as a right is therefore different from obtaining it from permission or privilege. Having a right is to have a convincing justification for acting purposively while remaining faithful to the respect of certain constraints."

The most relevant or most obvious human right one is confronted with while reflecting on the impacts of urbanization on human rights is the right to have an 
adequate living standard. This is put in Article 11 of the ICESCR as follows: "1. The States Parties to the present Covenant recognize the right of everyone to an adequate standard of living for himself and his family, including adequate food, clothing, and housing, and to the continuous improvement of living conditions. The States Parties will take appropriate steps to ensure the realization of this right, recognizing to this effect the essential importance of international co-operation based on free consent" (United Nations, 2020). Next to that right, also further rights, as well as right complexes, are concerned through urbanization processes, be it the right to non-discrimination, the access to natural resources, medical services, and the enjoyment of the highest attainable health standards (United Nations, 2020).

Those rights are already indicating that we are dealing here with a manifold spectrum of general interest in tackling the topic. What we were doing in the review is to analyze which topics and rights were tackled how and if we can draw general conclusions for the broad topic of impacts of urbanization processes on human rights. Before presenting the outcomes, the next chapter will explain how we proceeded to get the results.

\section{Research Process and Methods}

This section provides a concise description of the methodology adopted in this study and the research process we followed. This research's intent lies in a general interest in the intersection of urbanization and human rights. For this intersection, we initially aimed at getting, on the one hand, an in-depth look into the state of research on how ongoing and past urbanization processes were and are impacting human rights of urban and rural dwellers, and getting at the other hand, a helicopter-like perspective on the topic as such. Initially, we desperately looked for a systematic review to identify the gaps and ameliorate a reliable assessment of the existing literature, yet the preliminary literature search and analysis, unfortunately, showed no comprehensive review in the given context.

Hence, we purposefully conducted a systematic literature review to map the landscape of prevailing research and scrutinize state of the art concerning the impacts of urbanization on human rights. The performed systematic literature review collected different sources of data until the cut-off date of December 2019. Amidst mounds of various methods, this study embraces and implements the PRISMA concept-initially designed for medical reviews and currently also used in other disciplines (see Moher et al., 2009).

In pursuance of bringing scattered pieces of knowledge of different disciplines into a comprehensive review, the study collected and was limited to only peerreviewed journal articles in the two academic databases of Scopus and Web of Science. The review included publications from 1967 until 2019, and after duplicates were removed, a total of potential documents was identified, published over the past 53 years. The research process is illustrated in Figure 1 and further 


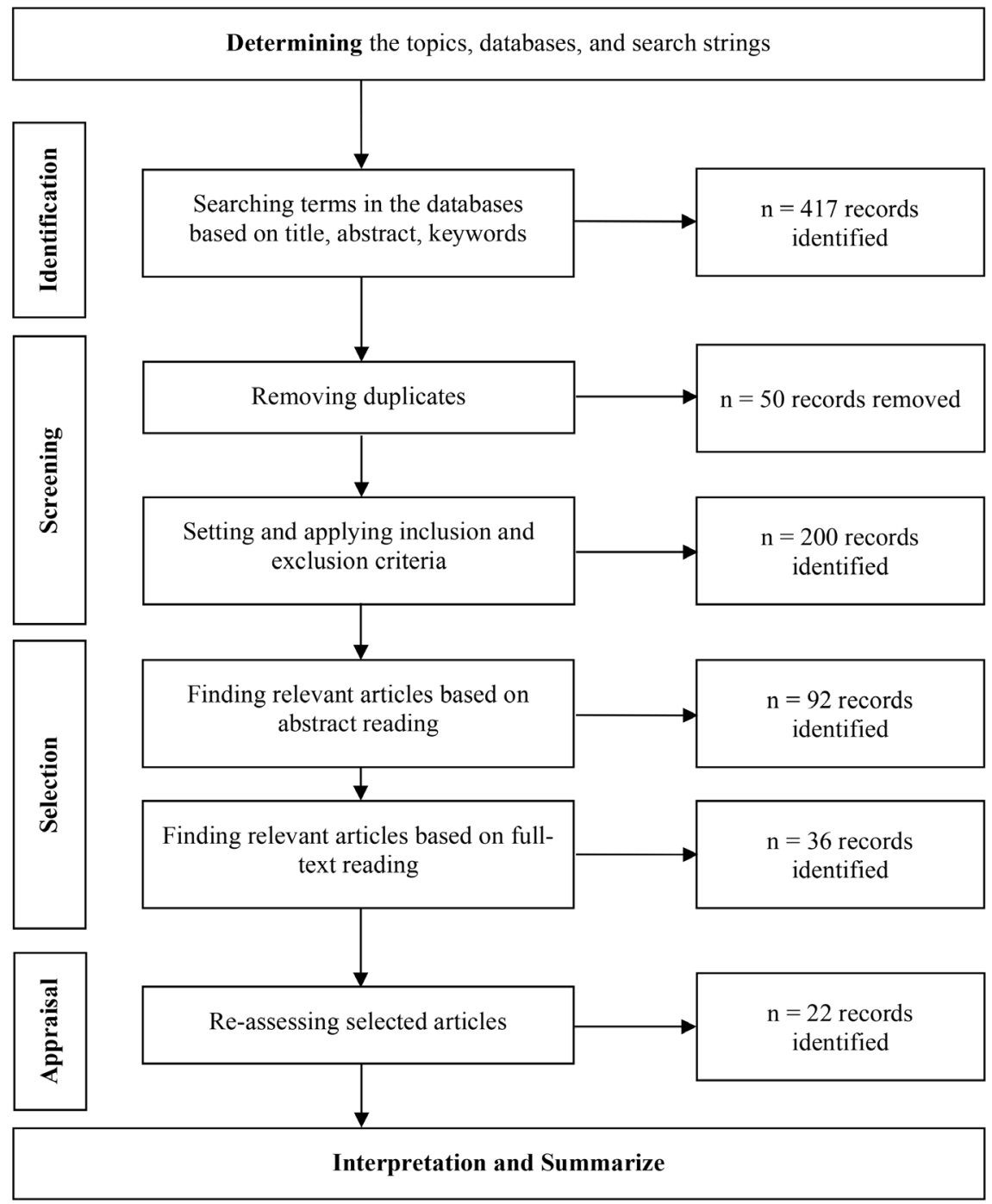

Figure 1. Research Process (adopted from Moher et al., 2009).

described below.

Specifically, the articles should mention expected or observed results, outcomes, or changes induced by urbanization; thus, their title, abstract, or keywords include two selected search strings. The first string, "urbani*," was combined with the second string, "human right ${ }^{*}$ ". The strings contain a wildcard symbol $\left({ }^{*}\right)$ to cover all the words containing the letters before the symbol, respectively spelling differences of urbanization and urbanization associated terms, e.g., urbanized, urbanizing, urbanism, and singular and plural form of human right(s). The first search string omits the publications that do not use the term of urbanization but might tackle issues of urbanization processes. We used the common general term for the second search string, but not the single human rights in their own terms. This way, we might have left out some papers, too. Nevertheless, as we searched for a general and broad overview, we kept up with the process, also due to pragmatic research reasons. 
Firstly, the review process began with an identification phase of articles, applying the selected search strings, urbani ${ }^{\star}$ AND "human right*", resulted in 264 articles in Scopus and 153 articles in Web of Science. Figure 2 renders the first pages of search results in the databases of Scopus and Web of Science, which also portrays some of the found articles in the identification phase. Secondly, the process continued by removing 50 pieces of duplicates. The literature was selected based on the following eligibility criteria: topic (related to urbanization and human rights), language (only articles in English), database (Scopus and Web of Science), publication status (only published), the publication year (until the cut-off date of December 2019), and document type (journal articles). The screening of the records later excluded unsuitable papers based on the preceding inclusion and exclusion criteria. The total sum of papers for analysis was reduced to 200 papers. Then, the abstracts were also read, and in ambiguous cases, each paper's full text was skimmed. Articles were then excluded from the total body of work for further analysis if they do not focus on (a) urbanization as a cause and (b) impacts on human rights as an effect. Hence records were reduced to the number of 92 (phase 1), respectively to the number of 36 (phase 2), and finally reached the number of 22 articles for further investigation.

Table 1 represents all the selected papers for final analysis with their authors, year of publication, and the published journals. The research is broad on observing

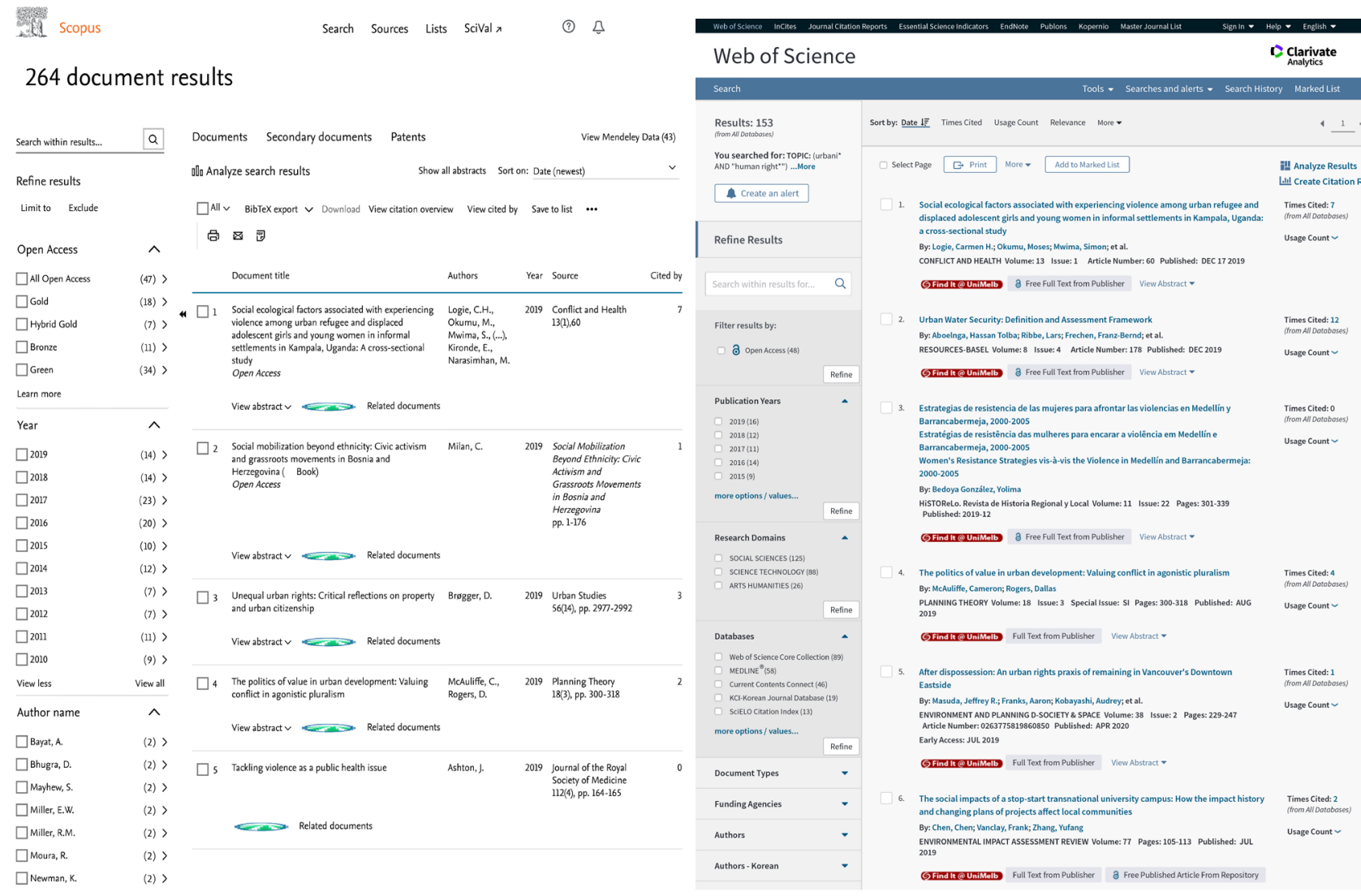

Figure 2. Screenshots from Scopus and Web of Science search results. 
urbanization processes, and there are also some, mainly case study papers of specific regions on the topic of urbanization impacts on (human) rights; however, a systematic review of the state of research on those lacks so far.

The publication dates range from 1983 to 2018 and differ, as can be seen, more explicitly in Figure 3. Some smaller waves can be detected during the last Table 1. Selected articles.

\begin{tabular}{|c|c|c|}
\hline Author (s) & Year & Journal \\
\hline Addaney et al. & 2018 & Australian Journal of Human Rights \\
\hline Aerni & 2016 & Sustainability \\
\hline Begum & 2007 & Social Policy and Administration \\
\hline Berrisford and Kihato & 2006 & Health and Human Rights \\
\hline Carmalt & 2014 & Development in Practice \\
\hline Chowdhury et al. & 2017 & South African Journal on Human Rights \\
\hline Coggin and Pieterse & 2015 & Policy Sciences \\
\hline Daniere and Takahashi & 1999 & Journal of Political Ecology \\
\hline Delgado-Ramos & 2015 & International Migration Review \\
\hline Drakakis-Smith & 1984 & Perspectives on Global Development and Technology \\
\hline Fonjong et al. & 2010 & Migration world magazine \\
\hline Johnnie & 1998 & South African Review of Sociology \\
\hline McGranahan et al. & 2016 & Environment and Urbanization \\
\hline Njoh & 2017 & Journal of Asian and African Studies \\
\hline Ogura & 1996 & Developing Economies \\
\hline Petrasek & 2014 & Sur international journal on human rights \\
\hline Rasella et al. & 2016 & Global Health Action \\
\hline Rossi-Espagnet & 1983 & Community development journal \\
\hline Safa & 1984 & International Migration Review \\
\hline Senese and Wilson & 2013 & Social Science \& Medicine \\
\hline Tura & 2017 & Nordic Journal of Human Rights \\
\hline Wisner & 1995 & Human Ecology \\
\hline
\end{tabular}

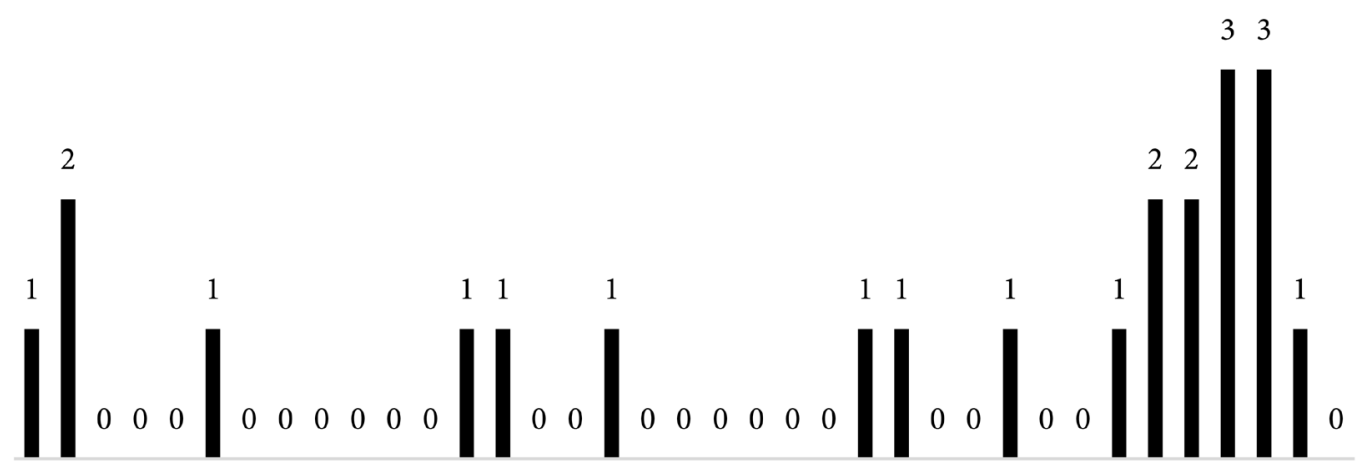

1983198519871989199119931995199719992001200320052007200920112013201520172019

Figure 3. Number of reviewed articles by publication year. 
decades, with missing literature on some years and a more substantial wave of the majority accumulating from 2013 to 2018 .

\section{Results and Discussion}

Urbanization processes, together with other developments, brought some of the most radical changes in society, economy, and environment. Contrary to be a sign of social and economic growth and cultural development, unplanned and unsustainable city growth has magnified instability, inequality, and human rights violations (Rossi-Espagnet, 1983). As the population grows, urban management becomes increasingly complex and rapid urbanization, especially the extension of large cities, and the correlated difficulties, i.e., poverty, unemployment, poor sanitation, inadequate health, urban slums, and environmental degradation, pose a formidable difficulty in both the developed and developing countries (Cohen, 2006). Hence, urbanization has simultaneous causality relation among mass migration, globalization, environmental, economic, and demographic changes.

As a consequence of this multitude of causing factors and their inter-linkages, it is complicated to detect urbanization as "the" cause of impacts on human rights. However, and acknowledging this interplay of different variables, it is tried within this review to collect and analyze the state of the research that focuses on urbanization processes and how they impact human rights.

It is observed that the reviewed articles address to various aspects of the link between urbanization processes and human rights and that they take different perspectives. Within this results and discussion section, we summarize the main identified topics; shed some light on specific points that are tackled in more than one paper. Those issues will be described below in more detail.

\subsection{Location Matters: Geographical Focus}

Urbanization is a process happening worldwide; however, its impact on human rights is far from homogenous due to locational differences in administrative, economic, and political contextual structures (Alkema et al., 2013; Ooi \& Phua, 2007). At the first look, this might make it hard to compare studied countries and regions in the literature, as well as our review findings; however, as earlier mentioned, it is not intended to compare results but to bring them together firsthand and human rights are factual and do not differ based on a location. Ten studies reported findings from Africa, three studies from Asia, four articles focused on developing regions in Latin America, and one in each from the US and Canada. The dominance of studies focusing on Africa was not surprising given the significant role of urbanization pace compared to significant economic and industrial expansion (Preston, 1979; Ray \& Borer, 2018).

Human rights are crucial for both developed and developing nations (Carmalt, 2014). Although the reviewed literature points out that only two reviewed articles studied developed nations of Canada (Carmalt, 2014) and the USA (Senese \& Wilson, 2013), the unstable growth of cities around the world endangers to 
become one of the major problems of our urban habitat (Rossi-Espagnet, 1983). However, rapid urbanization and unplanned operations are some of the main factors creating human rights violations in developing countries (Addaney et al., 2018; Begum, 2007; Berrisford \& Kihato, 2006). All reviewed articles except four (Aerni, 2016; McGranahan et al., 2016; Petrasek, 2014; Rossi-Espagnet, 1983), which have no study focus but give a general approach to the impacts of urbanization on human rights, provide site-specific case studies and address cities, countries, or regions. Table 2 displays all those reviewed articles and their site-specific localities by countries and wider regions-symbolized with an asterisk such as Sub-Saharan Africa and the African continent in general, which articles do not strictly focus on a specific case in a country but focus on general human rights implications in more expansive areas.

\subsection{Focus on Interlinked Problems and Solutions-Fair and Sustainable Land Use}

Looking at the focus of the articles, if they are more problem-oriented or more oriented towards solutions to overcome these problems, some articles mainly talk about solutions and which type of actions are needed to be taken in order to overcome human rights violations (Addaney et al., 2018; Chowdhury et al., 2017; Rossi-Espagnet, 1983). However, they and other selected articles also state the problem caused by or related to urbanization processes.

Table 2. Geographical distribution of reviewed articles

\begin{tabular}{|c|c|c|}
\hline Geographical Distribution & Number of Article (s) & Article (s) \\
\hline USA & 1 & Senese \& Wilson, 2013 \\
\hline Canada & 1 & Carmalt, 2014 \\
\hline Brazil & 1 & Rasella et al., 2016 \\
\hline Haiti & 1 & Berrisford \& Kihato, 2006 \\
\hline Puerto Rico & 1 & Safa, 1984 \\
\hline Mexico & 1 & Daniere \& Takahashi, 1999 \\
\hline Bangladesh & 2 & Begum, 2007 and Carmalt, 2014 \\
\hline Thailand & 1 & Coggin \& Pieterse, 2015 \\
\hline South Africa & 3 & Wisner, 1995 and Ogura, 1996 \\
\hline Ethiopia & 1 & Tura, 2017 \\
\hline Nigeria & 1 & Fonjong et al., 2010 \\
\hline Cameroon & 2 & Drakakis-Smith, 1984 and Njoh, 2017 \\
\hline Zimbabwe & 1 & Delgado-Ramos, 2015 \\
\hline Sub-Saharan Africa ${ }^{*}$ & 1 & Johnnie, 1998 \\
\hline Africa $^{*}$ & 1 & Addaney et al., 2018 \\
\hline Unspecified & 4 & $\begin{array}{l}\text { Aerni, 2016; McGranahan et al., 2016; } \\
\text { Petrasek, 2014; Rossi-Espagnet, } 1983\end{array}$ \\
\hline
\end{tabular}


Urbanization coupled with existing spatial inequalities exacerbates individuals' and communities' vulnerability to a potential natural disaster; it principally yields a call to action for the public sector to lay emphasis on appropriate landuse policies and development strategies (Carmalt, 2014). National and local authorities are undoubtedly not the only ones responsible for considering a human rights' perspective in the urban planning process, but the private sector should also pay attention to environmental and social sustainability in their actions (Addaney et al., 2018). For instance, a master plan, as one of the planning tools, is an essential instrument of development and a framework for guiding the public and private sector to consider prevailing and potential problems and for the expected urban growth (Begum, 2007). Such a master plan is a long-term planning document to guide future growth and development, including proposals and projections for particular domains such as the economy, environment, communication, and housing, all of which impact residents' well-being and human rights. Hence, in coordination with a master plan, the urbanization process should carry a human rights-based approach and bring urban actors aligned to augment urbanizing communities' livability, elevate society's most marginalized groups, protect environmental assets, and strengthening resilience to the consequences of these processes and climate change impacts (Addaney et al., 2018; Mensah, 2014; Schrijver, 2016).

\subsection{Urbanization with Adverse and Beneficial Impacts}

Even though urbanization processes have been associated with human development and progress (Rossi-Espagnet, 1983), they are twofold and can positively and negatively impact human rights. In total, nine articles depict positive impacts, while all the 22 articles emphasize negative consequences related to urbanization processes.

Urbanization has potential positive impacts on human rights in terms of enhancing the quality of the urban environment while building an adequate standard of living (Berrisford \& Kihato, 2006), which results to improve livelihoods (Addaney et al., 2018; Aerni, 2016; McGranahan et al., 2016) for all residents if it is governed, planned and designed carefully (McGranahan et al., 2016) and taking care of the global power shifts (Petrasek, 2014). Urbanization coupled with economic growth (Chowdhury et al., 2017) can challenge urban poverty (Addaney et al., 2018; Chowdhury et al., 2017) and expand access to shelter, food, and employment (Petrasek, 2014). Through planned and regulated processes, it can confront disasters with the help of resilient urban actions (Aerni, 2016) and sustainable solutions (McGranahan et al., 2016). There are also decisive advantages of concentration of people and firms within urban agglomerations, regarding consequences such as decreased transportation costs, dense labor markets, or the free flow of knowledge (Ciccone \& Hall, 1996; Petrasek, 2014).

Urbanization might also drive additional beneficial outcomes for gender equality and better opportunities for strengthening vulnerable groups, especially women 
(Fonjong et al., 2010) through providing better access to secondary education, primary health care, medical services, and workforce (Johnnie, 1988; Petrasek, 2014). As long as the pace and level of urbanization proceeds at a reasonable and controlled condition and a broad spectrum of urban actors involved in the process, urbanization might cause, ultimately, positive outcomes (McGranahan et al., 2016; Rossi-Espagnet, 1983).

Urbanization and urban space are crucial in the development and diversification of human rights. Urban space, eventually, can be the starting place for the emergence of new thoughts on human rights and related developments. In other words, comprehensive and inclusive sustainable development, resilience to future challenges, and controlled urbanization can be a robust groundwork for the attainment of human rights (McGranahan et al., 2016).

The negative impacts in the selected literature, on the other hand, are relatively less mentioned than the positive issues. They highlight the side effects of excessive population growth. Urban population growth, coupled with inequalities and associated concerns, can challenge the overall development of cities to be cause of several intertwined problems, such as economic burden and obstacles (Drakakis-Smith, 1984; Rossi-Espagnet, 1983) and violation of rights to life, health, property and culture (Addaney et al., 2018).

Considering the lack of employment opportunities in rural areas, urbanization induced by rural-to-urban migration exacerbates existing challenges of (daily) income opportunities (Aerni, 2016; Begum, 2007; Daniere \& Takahashi, 1999; Wisner, 1995), employment (Fonjong et al., 2010; Safa, 1984) and secure working conditions (McGranahan et al., 2016; Ogura, 1996) and ultimately resulting in urban poverty (Delgado-Ramos, 2015; McGranahan et al., 2016; Senese \& Wilson, 2013).

Urbanization significantly influences the adequate standard of living such as food, medicine, clothing, housing, and water (Addaney et al., 2018; Begum, 2007; Johnnie, 1988; Ogura, 1996), inflame food insecurity and health implications (Fonjong et al., 2010; Ogura, 1996; Rossi-Espagnet, 1983; Senese \& Wilson, 2013; Tura, 2017). Furthermore, it can affect procedural rights such as access to information, access to justice, and judicial remedy (Addaney et al., 2018). It generates a lack of suitable, adequate, and affordable housing (Addaney et al., 2018; Aerni, 2016; Begum, 2007; Daniere \& Takahashi, 1999; Johnnie, 1988; RossiEspagnet, 1983; Wisner, 1995) and urbanization processes and the government actions may limit the property rights of individuals or groups of residents (Addaney et al., 2018; Begum, 2007; Chowdhury et al., 2017; Fonjong et al., 2010; Tura, 2017).

Cities' rapid expansion, notably in the developing world, induces service demand and use, and imposes an unsustainable strain on the physical environment and infrastructure (Rossi-Espagnet, 1983). The lack of established infrastructure and urban facilities to balance the increasing population demands gives residents insufficient access to public services such as education (Begum, 2007; Coggin \& 
Pieterse, 2015; McGranahan et al., 2016), health facilities (Addaney et al., 2018; Carmalt, 2014; Coggin \& Pieterse, 2015; Daniere \& Takahashi, 1999; McGranahan et al., 2016; Rasella et al., 2016; Wisner, 1995), water sewage, electricity and sanitation (Carmalt, 2014; Johnnie, 1988; McGranahan et al., 2016; Ogura, 1996; Petrasek, 2014; Rossi-Espagnet, 1983; Wisner, 1995), as well as public transportation (Carmalt, 2014; Coggin \& Pieterse, 2015; Daniere \& Takahashi, 1999; Rossi-Espagnet, 1983; Wisner, 1995).

It overall significantly worsens pre-disaster inequalities (Carmalt, 2014), eventually creates violence and insecurity (Petrasek, 2014; Wisner, 1995) towards the physical well-being of vulnerable groups such as women and children (Fonjong et al., 2010), advances racial and gender-based discrimination (Aerni, 2016; Carmalt, 2014; Fonjong et al., 2010; McGranahan et al., 2016; Ogura, 1996; Senese \& Wilson, 2013) and social exclusion (McGranahan et al., 2016).

Governments perceived development merely as a trigger point for economic gain and did not consider its involvement in human rights progress for decades (Uvin, 2007), which may be the causing factor of adverse impacts resulting from rapid and unplanned urbanization. However, rapid urbanization has strengthened efforts to alleviate poverty and promote the living conditions in Africa (Addaney et al., 2018). Socio-economic empowerment led by urbanization improves human rights access and guarantees that communities are more sustainable, inclusive, and resilient (Aerni, 2016). All of the reviewed articles, on the other hand, indicate that rapid, uncontrolled, and unsustainable urbanization models, which any region observes in the world, are rendering cities into a central point for social conflicts, economic crises and environmental hazards. Furthermore, it might get apparent to developing nations to witness concerns and issues regarding human rights, but the developed nations also perceive related problems (Carmalt, 2014).

\subsection{Vulnerable and Affected Groups}

The surveyed literature addressed particular groups exposed to disadvantaged situations in terms of human rights or merely affected by urbanization processes based on person's class, gender, age, ethnicity, and whether or not one is disabled (Wisner, 1995). The articles portray one or more affected population groups by urbanization processes such as urban poor, workers, smallholders, (racial and ethnic) minorities, indigenous communities, and mostly (and within those groups) migrants or non-citizens, women, children, elderly people, and people with disabilities.

The relationship between urbanization processes and spatial inequality creates a central argument for the public sector that policies should prioritize fair landuse and development strategies for reducing already existing vulnerability to natural hazards and unprecedented events considering human rights (Carmalt, 2014). In fact, international legal obligations protect individuals' property and livelihoods in Article 11 (I) of the International Covenant on Economic Social and 
Cultural Rights (CESCR). The development of vulnerable individuals' and communities' rights demonstrates adverse impacts on health, food, water, and housing because vulnerable groups such as minorities and women confide in the utility of forest, agricultural land, and water resources for survival and development (Addaney et al., 2018). Concerning those interlinkages, there are particular human rights violations and affected groups, which may cause further social discrimination, including assimilation, exclusion, racial and gender imbalance (Chowdhury et al., 2017; McGranahan et al., 2016; Njoh, 2017; Ogura, 1996; Safa, 1984; Senese \& Wilson, 2013). Functioning services of ecosystems provide clean drinking water, nutrition, food potency and resilience (Addaney et al., 2018; Delgado-Ramos, 2015; Petrasek, 2014; Rossi-Espagnet, 1983), as well as contribute directly and indirectly to recreation, land fertility, protection from natural hazards, as well as to people's mental health and well-being anywhere in the world (Addaney et al., 2018). Thus, groups, which are already vulnerable due to different reasons, either in developing or developed countries, are affected by urbanization processes and the decrease in respective ecosystem services.

The protection of the necessary environmental assets provided by nature and a healthy ecosystem is indispensable to any resident's well-being. However, activities associated with the rapid expansion of urban land generate impacts often violating the rights of indigenous peoples, including the rights to life, health, property, and culture, and often considered to be the obstacles of human rights realization, also of children's rights to health and their access to related services (Addaney et al., 2018). Due to their bond to their lands, nature, and natural resources, certain groups may be individually vulnerable to environmental threats, such as indigenous peoples (Voigt \& Grant, 2015). Ultimately, everyone's rights, including adequate food, water, housing, protection, clothing, and continuous improvement of these assets, must be an adequate standard of living conditions (Berrisford \& Kihato, 2006). Urbanization and human rights are situated in a complex picture of interlinkages between different problems and contextual factors. Thus, it is very unclear to set the picture and draw simple cause-effect relationship arrows. However, some parts of the picture appear sharper than others, while none of them can be detected in all their very aspects and details and brought to the general surface, as the reviewed articles take on very different viewpoints to the link of urbanization and human rights. They also refer to various places with differences in economic and social development at national levels, social and political institutions of countries, and historical and geographical conditions, producing complicated international comparisons (Hussain \& Imitiyaz, 2018; Macura, 1961). Nevertheless, the aim of the research is not to compare different case studies but to bring together so far reached results of adverse and beneficial impacts of urbanization processes on human rights.

It must not be forgotten that the findings embody some limitations due to several factors throughout the research process. First, this systematic review did 
not capture all the studies on a given topic in the literature. The first search string probably omitted some publications that do not use the term of urbanization but focused on the specific issues related to urbanization without mentioning the term such as property, health, discrimination, which are discussed in the selected articles at the result section, urbanization with adverse and beneficial impacts. It might have also not captured a limited number of articles due to some exclusion criteria (e.g., books, book chapters and papers published in languages other than English) and the inclusion from only two comprehensive databases of Scopus and Web of Science. However, this approach allowed us to collect the 200 articles and initially analyze 22 articles with more inclusive rigor. Secondly, it was not easy to compare impacts and outcomes moderately since the lack of a unified definition of urbanization creates considerable challenges (Dorélien et al., 2013; Hussain \& Imitiyaz, 2018; Kasarda \& Crenshaw, 1991). Although these limitations might hinder the dissemination, it is still crucial to spot the need for understanding the currency of the impact of urbanization in different populations.

\section{Conclusion}

This paper provides an overview of the state of research on the impacts of urbanization processes on human rights and the linkages to other global change processes, contextual settings, and local problems such as environmental degradation, while it also reports on the solutions to overcome the adverse impacts through planning, fair access rights, and sustainable land use, which might be helpful for continued research on urbanization trends and consequent human rights impacts. The underlying assumptions proposed herein can support more definite studies whose results will have meaningful implications for further analysis. Moreover, further studies are required to assess better the factors affecting the prevalence of urbanization.

The reviewed literature brought together different aspects such as interlinkages with other global change processes, geographical foci of research, challenges and opportunities of urbanization processes, and positive and negative consequences on human rights. Due to contextual factors, location matters, but the impacts of urbanization on human rights are not only a question of the respective country's development status. Also, within developed countries, adverse impacts are reported, while the majority of studies report on developing and, to a lesser extent, emerging countries.

There are several human rights at stake, which can be impacted adversely or beneficially through urbanization processes. As some studies report, urbanization is not necessarily a harmful act but can have many beneficial aspects. The study also shows examples focused on solutions to overcome human rights violations through urbanization. The urbanization processes are linked to other problems, e.g., natural hazards, environmental degradation, or access rights. Hence, a potential solution might present sustainable land use and fair distribution of 
the access, where planned and steered urbanization together with the protection of environmental assets can support reaching that. However, it remains a severe challenge faced with ongoing rapid urbanization processes. Pursuing to curtail economic development can expand urban sprawl and the number of informal settlements, less affordable housing, and growing (also small) business costs. It will, namely, favor the rich and abuse the poor. On the other hand, deriving social and economic empowerment by better-planned urbanization processes improves access to basic human rights and makes it possible for communities to become more inclusive, agile, robust, and sustainable. Empowered individuals can better find shelter, food, employment security, and better access to education. Other positive outcomes may emerge from the growth of the urban population and population concentration, enhancing access to fundamental human rights, including higher education and health care in an urban setting (Petrasek, 2014).

The negative impacts of urbanization are generally seen as more reported than the beneficial impacts and referred to the rapid urbanization processes and their interlinkages to other before-mentioned problems. The following items are common threads concerning human rights issues identified in the literature review: environment, housing, infrastructure, economy, socio-culture, and politics. It is observed that urban growth leads to apparent tension between at least two sets of national priorities of countries where rapid urbanization occurs: (1) to accelerate attempts to revive and encourage economic growth and (2) to enhance public health and welfare. Environmental conditions have deteriorated exceptionally and rapidly in the face of rapid industrialization and urbanization. Furthermore, rapid urbanization has adverse impacts also on health problems, family instability, social problems (drugs, evictions, and congestion), income disadvantage, water (poor water quality and untreated wastewater), environmental problems (noise and air pollution, dust); traffic, and a lack of adequate housing (Daniere \& Takahashi, 1999). Urbanization processes are explicitly contributing and worsening the adverse situation of continuingly discriminated vulnerable and specific social groups. While mainly un-steered rapid urbanization occurs above all in the geographical foci regions, specific social groups' discrimination is not an exclusive question of the developing country or a geographical region.

As urbanization has concurrently adverse and beneficial impacts on human rights, it is indispensable to investigate further how solutions exactly overcome the adverse impacts, especially on already vulnerable groups, and how they can reconcile best to contextual factors in interaction with other change processes.

\section{Conflicts of Interest}

The authors declare no conflicts of interest regarding the publication of this paper.

\section{References}

Addaney, M., Boshoff, E., \& Nyarko, M. G. (2018). Protection of Environmental Assets in Urban Africa: Regional and Sub-Regional Human Rights and Practical Environmental 
Protection Mechanisms. Australian Journal of Human Rights, 24, 182-200. https://doi.org/10.1080/1323238X.2018.1480235

Aerni, P. (2016). Coping with Migration-Induced Urban Growth: Addressing the Blind Spot of UN Habitat. Sustainability, 8 , Article No. 800. https://doi.org/10.3390/su8080800

Alkema, L., Jones, G. W., \& Lai, C. U. R. (2013). Levels of Urbanization in the World's Countries: Testing Consistency of Estimates Based on National Definitions. Journal of Population Research, 30, 291-304. https://doi.org/10.1007/s12546-013-9109-x

Anderson, N. (1959). Urbanism and Urbanization. American Journal of Sociology, 65, 6873. https://doi.org/10.1086/222628

Banerjee, S., \& De, D. (2014). Level of Urbanization: An Empirical Study of North 24 Parganas. International Research Journal of Social Sciences, 3, 12-20.

Begum, A. (2007). Urban Housing as an Issue of Redistribution through Planning? The Case of Dhaka City. Social Policy \& Administration, 41, 410-418. https://doi.org/10.1111/j.1467-9515.2007.00563.x

Berrisford, S., \& Kihato, M. (2006). The Role of Planning Law in Evictions in Sub-Saharan Africa. South African Review of Sociology, 37, 20-34. https://doi.org/10.1080/21528586.2006.10419144

Carmalt, J. (2014). Prioritizing Health: A Human Rights Analysis of Disaster, Vulnerability, and Urbanization in New Orleans and Port-au-Prince. Health and Human Rights, 16, 41-53.

Chowdhury, M. R., Jahan, F., \& Rahman, R. (2017). Developing Urban Space: The Changing Role of NGOs in Bangladesh. Development in Practice, 27, 260-271. https://doi.org/10.1080/09614524.2017.1287162

Ciccone, A., \& Hall, R. E. (1996). Productivity and the Density of Economic Activity. American Economic Review, 86, 54-70.

Coggin, T., \& Pieterse, M. (2015). A Right to Transport? Moving towards a Rights-Based Approach to Mobility in the City. South African Journal on Human Rights, 31, 294314. https://doi.org/10.1080/19962126.2015.11865248

Cohen, B. (2006). Urbanization in Developing Countries: Current Trends, Future Projections, and Key Challenges for Sustainability. Technology in Society, 28, 63-80. https://doi.org/10.1016/j.techsoc.2005.10.005

Corradetti, C. (2009). Relativism and Human Rights: A Theory of Pluralistic Universalism. Springer. https://doi.org/10.1007/978-1-4020-9986-1

Daniere, A. G., \& Takahashi, L. M. (1999). Poverty and Access: Differences and Commonalties Across Slum Communities in Bangkok. Habitat International, 23, 271-288. https://doi.org/10.1016/S0197-3975(98)00052-6

Davis, K. (1955). The Origin and Growth of Urbanization in the World. American Journal of Sociology, 60, 429-437. https://doi.org/10.1086/221602

Davis, K. (1965). The Urbanization of the Human Population. Scientific American, 213, 40-53. https://doi.org/10.1038/scientificamerican0965-40

Delgado-Ramos, G. C. (2015). Water and the Political Ecology of Urban Metabolism: The Case of Mexico City. Journal of Political Ecology, 22, 98-114.

https://doi.org/10.2458/v22i1.21080

Dorélien, A., Balk, D., \& Todd, M. (2013). What Is Urban? Comparing a Satellite View with the Demographic and Health Surveys. Population and Development Review, 39, 413439. https://doi.org/10.1111/j.1728-4457.2013.00610.x 
Drakakis-Smith, D. W. (1984). The Changing Economic Role of Women in the Urbanization Process: A Preliminary Report from Zimbabwe. International Migration Review, 18, 1278-1292. https://doi.org/10.1177/019791838401800419

Fonjong, L., Sama-Lang, I., \& Fon, F. L. (2010). An Assessment of the Evolution of Land Tenure System in Cameroon and Its Effects on Women's Land Rights and Food Security. Perspectives on Global Development and Technology, 9, 154-169. https://doi.org/10.1163/156914910X487979

Gibbs, J. P. (1966). Measures of Urbanization. Social Forces, 45, 170-177. https://doi.org/10.2307/2574387

Glaeser, E. L., \& Steinberg, B. M. (2017). Transforming Cities: Does Urbanization Promote Democratic Change? Regional Studies, 51, 58-68. https://doi.org/10.1080/00343404.2016.1262020

Hauser, P. M., \& Duncan, O. D. (1959). The Study of Population: An Inventory and Appraisal. University of Chicago Press.

Hawley, A. H. (1967). The Study of Urbanization. Demography, 4, 937-941. https://doi.org/10.2307/2060330

Heilinger, J. C. (2011). The Moral Demandingness of Socioeconomic Human Rights. In E. Gerhard, \& J. C. Heilinger (Eds.), The Philosophy of Human Rights: Contemporary Controversies (pp. 185-208). De Gruyter. https://doi.org/10.1515/9783110263886.185

Henderson, V. (2002). Urbanization in Developing Countries. World Bank Research Observer, 17, 89-112. https://doi.org/10.1093/wbro/17.1.89

Hussain, M., \& Imitiyaz, I. (2018). Urbanization Concepts, Dimensions and Factors. International Journal of Recent Scientific Research, 9, 23513-23523.

Johnnie, P. B. (1988). Rural-Urban Migration in Nigeria: Consequences on Housing, HealthCare and Employment. Migration World, 16, 22-29.

Kasarda, J. D., \& Crenshaw, E. M. (1991). Third World Urbanization: Dimensions, Theories, and Determinants. Annual Review of Sociology, 17, 467-501.

https://doi.org/10.1146/annurev.so.17.080191.002343

Lampard, E. E. (1965). Historical Aspects of Urbanization. In P. M. Hauser, \& L. F. Schnore (Eds.), The Study of Urbanisation (pp. 519-554). Wiley.

Macura, M. (1961). The Influence of the Definition of the Urban Place on the Size of the Urban Population. In J. P. Gibbs (Ed.), Urban Research Methods (pp. 21-31). Literary Licensing.

McGranahan, G., Schensul, D., \& Singh, G. (2016). Inclusive Urbanization: Can the 2030 Agenda Be Delivered without It? Environment and Urbanization, 28, 13-34. https://doi.org/10.1177/0956247815627522

Mensah, C. A. (2014). Destruction of Urban Green Spaces: A Problem beyond Urbanization in Kumasi City, Ghana. American Journal of Environmental Protection, 3, 1-9. https://doi.org/10.11648/j.ajep.20140301.11

Mihr, A. (2010). Urbanization and Human Rights. 2009 Amsterdam Conference on the Human Dimensions of Global Environmental Change, Volendam, 2-4 December 2009, $1-32$.

Mitchell, J. C. (1956). Social Implications of Industrialization and Urbanization in Africa South of the Sahara. United Nations Educational, Scientific and Cultural Organization (UNESCO).

Moher, D., Liberati, A., Tetzlaff, J., \& Altman, D. G. (2009). Preferred Reporting Items for Systematic Reviews and Meta-Analyses: The PRISMA Statement. PLoS Medicine, 6, 
e1000097. https://doi.org/10.1371/journal.pmed.1000097

Njoh, A. J. (2017). “The Right-To-The-City Question” and Indigenous Urban Populations in Capital Cities in Cameroon. Journal of Asian and African Studies, 52, 188-200. https://doi.org/10.1177/0021909615570954

Ogura, M. (1996). Urbanization and Apartheid in South Africa: Influx Controls and Their Abolition. The Developing Economies, 34, 402-423. https://doi.org/10.1111/j.1746-1049.1996.tb01178.x

Ooi, G. L., \& Phua, K. H. (2007). Urbanization and Slum Formation. Journal of Urban Health, 84, 27-34. https://doi.org/10.1007/s11524-007-9167-5

Petrasek, D. (2014). Global Trends and the Future of Human Rights Advocacy. SUR, No. 20, 44-55.

Preston, S. H. (1979). Urban Growth in Developing Countries: A Demographic Reappraisal. Population and Development Review, 5, 195-215. https://doi.org/10.2307/1971823

Rasella, D., Machado, D. B., Castellanos, M. E. P., Paim, J., Szwarcwald, C. L., Lima, D., Magno, L., Pedrana, L., Medina, M. G., Penna, G. O., \& Barreto, M. L. (2016). Assessing the Relevance of Indicators in Tracking Social Determinants and Progress toward Equitable Population Health in Brazil. Global Health Action, 9, Article No. 29042. https://doi.org/10.3402/gha.v9.29042

Ray, R., \& Borer, M. I. (2018). Chapter 27: Urbanism and Urbanization. In A. Javier Treviño (Ed.), The Cambridge Handbook of Social Problems (Vol. 2, pp. 475-488). Cambridge University Press. https://doi.org/10.1017/9781108550710.028

Rossi-Espagnet, A. (1983). Primary Health Care in the Context of Rapid Urbanization. Community Development Journal, 18, 104-119. https://doi.org/10.1093/cdj/18.2.104

Safa, H. I. (1984). Female Employment and the Social Reproduction of the Puerto Rican Working Class. International Migration Review, 18, 1168-1187. https://doi.org/10.1177/019791838401800413

Schrijver, N. (2016). Managing the Global Commons: Common Good or Common Sink? Third World Quarterly, 37, 1252-1267. https://doi.org/10.1080/01436597.2016.1154441

Senese, L. C., \& Wilson, K. (2013). Aboriginal Urbanization and Rights in Canada: Examining Implications for Health. Social Science \& Medicine, 91, 219-228. https://doi.org/10.1016/j.socscimed.2013.02.016

Simon, D., McGregor, D., \& Nsiah-Gyabaah, K. (2004). The Changing Urban-Rural Interface of African Cities: Definitional Issues and an Application to Kumasi, Ghana. Environment and Urbanization, 16, 235-248. https://doi.org/10.1630/0956247042309856

Tasioulas, J. (2012). On the Nature of Human Rights. In E. Gerhard, \& J.-C. Heilinger (Eds.), The Philosophy of Human Rights: Contemporary Controversies (pp. 17-60). De Gruyter. https://doi.org/10.1515/9783110263886.17

Tisdale, H. (1942). The Process of Urbanization. Social Forces, 20, 311-316. https://doi.org/10.2307/3005615

Tura, H. A. (2017). Linking Land Rights and the Right to Adequate Food in Ethiopia: Normative and Implementation Gaps. Nordic Journal of Human Rights, 35, 85-105. https://doi.org/10.1080/18918131.2017.1312860

Uchida, H., \& Nelson, A. (2010). Agglomeration Index: Towards a New Measure of Urban Concentration. In J. Beall, B. Guha-Khasnobis, \& R. Kanbur (Eds.), Urbanization and Development: Multidisciplinary Perspectives (pp. 1-16). Oxford University Press. https://doi.org/10.1093/acprof:oso/9780199590148.003.0003 
United Nations (2019a). World Population Prospects 2019: Highlights. https://population.un.org/wpp/Publications/Files/WPP2019 Highlights.pdf

United Nations (2019b). World Urbanization Prospects: The 2018 Revision. https://www.un-ilibrary.org/population-and-demography/world-urbanization-prospec ts-the-2018-revision b9e995fe-en

United Nations (2020). Treaty Collection. Chapter 4 Human Rights. 3. International Covenant on Economic, Social and Cultural Rights, New York, 16 December 1966.

https://treaties.un.org/Pages/ViewDetails.aspx?src=TREATY\&mtdsg no=IV-3\&chapte $\underline{\mathrm{r}=4 \& \text { clang }=\text { en }}$

Uvin, P. (2007). From the Right to Development to the Rights-Based Approach: How 'Human Rights' Entered Development. Development in Practice, 17, 597-606. https://doi.org/10.1080/09614520701469617

Vlahov, D. (2002). Urbanization, Urbanicity, and Health. Journal of Urban Health, 79, S1S12. https://doi.org/10.1093/jurban/79.suppl 1.S1

Voigt, C., \& Grant, E. (2015). Editorial: The Legitimacy of Human Rights Courts in Environmental Disputes. Journal of Human Rights and the Environment, 6, 131-138. https://doi.org/10.4337/jhre.2015.02.00

Wisner, B. (1995). The Reconstruction of Environmental Rights in Urban South Africa. Human Ecology, 23, 259-284. https://doi.org/10.1007/BF01191652

Yilong, S. (1996). One Model of Chinese Urbanization-The Urbanization Process in Xiamen City's Caitang Village. Chinese Sociology and Anthropology, 28, 8-33.

https://doi.org/10.2753/CSA0009-462528048 